\title{
PARA ALÉM das CRÍTICAS: ACOLHIMENTO, ACEITAÇÃo E ESPAÇOS DE DIÁlOGO. A CONTRIBUIÇÃO DOS PROJETOS ESPORTIVOS DE ONGS NA EDUCAÇÃO E FORMAÇÃO HUMANA DE ADOLESCENTES
}

\author{
BEYOND THE CRITICS: ACCEPTANCE AND DIALOGUE PLACES. THE CONTRIBUTION \\ OF NGOS SPORT PROJECTS TO ADOLESCENTS EDUCATION AND HUMAN \\ DEVELOPMENT.
}

\author{
Ângela de Carvalho Bernardes \\ Mestra em Educação \\ Universidade Nove de Julho - UNINOVE \\ São Paulo, SP - Brasil. \\ angeladecbernardes@gmail.com.
}

\begin{abstract}
Resumo: O presente artigo resulta de pesquisa de mestrado e propõe reflexões sobre adolescentes participantes de projetos esportivos em Organizações Não Governamentais (ONGs). O significado que essas instituições têm para eles configura o objeto da investigação. A compreensão dos adolescentes sobre a influência dessas organizações em sua educação e formação humana caracteriza o contexto das reflexões, que se fundamentam teoricamente no pensamento complexo. Essa forma de pensar sugere uma educação aberta e inclui o sujeito no processo. Por meio da realização de entrevistas abertas com 23 adolescentes de três ONGs de São Paulo e região, produziu-se inferências sobre o objeto investigado, caracterizando o estudo como qualitativo. Os resultados indicam que os adolescentes percebem as ONGs como espaços de educação e formação humana, sobretudo pelo acolhimento dado a eles, pela afetividade nas relações e pelas estratégias educacionais utilizadas, com destaque para os professores como maiores responsáveis por esses aspectos.
\end{abstract}

Palavras-chave: adolescente; esporte; ONG; pensamento complexo.

Abstract: This article comes from a master's degree research and suggests thinking about adolescents and the sport projects of Non-Governmental Organizations they take part in. The meaning of the NGOs for the adolescents is the object of the study. The comprehension about the influence of these organizations in their education and human development outlines the problem of research. The complex thought supports the study theoretically, referring to a wide education, and brings the person back to the research process. It is qualitative research, which accomplished 23 unstructured interviews with adolescents from three NGOs in São Paulo and region. The data analysis produces inferences about the research object, supported by the theoretical reference. The findings point to the perception of the adolescents about the NGOs as places of education and human development, most because of the way they are accepted, the affectivity of the relationships and the educational strategies, with the teachers as the main responsible for these elements.

Keywords: adolescent; sport; NGO; complex thought.

Para citar-ABNT NBR 6023:2018

BERNARDES, Ângela de Carvalho. Para além das críticas: acolhimento, aceitação e espaços de diálogo. A contribuição dos projetos esportivos de ONGs na educação e formação humana de adolescentes. Cadernos de Pós-graduação, São Paulo, v. 20, n. 1, p. 176-188, jan./jun. 2021. Disponível em: https://doi.org/10.5585/cpg.v20n1.18525. 


\section{Introdução}

O ponto de partida das reflexões propostas é o reconhecimento de que as Organizações Não Governamentais (ONGs) ou Organizações da Sociedade Civil (OSCs), termo mais recente para ONG (MROSC, 2014), ocupam espaços abertos pelo Estado brasileiro, em função de um caminho adotado por governos, principalmente a partir da década de 1990, que passaram a priorizar o desenvolvimento econômico em detrimento de uma política de garantia de direitos (Gohn, 2005).

Sob outra perspectiva, Telles (1999) ressalta a importância dessas instituições que conjugam Estado e sociedade e que oferecem possibilidades de acesso, principalmente, à população excluída de uma vida social organizada. As ONGs configuram-se como espaços possíveis de construção de políticas sociais, com propósitos de efetivação de direitos constitucionais, em especial para a população em situações de exclusão, que se encontra, por vezes, alijada até mesmo de políticas voltadas a ela (TELLES, 1999). Pode-se dizer, por exemplo, que o reconhecimento do esporte como direito está distante da realidade de crianças e adolescentes brasileiros e que tem sido integrado a outros direitos, como educação, lazer, trabalho etc., para que seja efetivado (BERCLAZ; LOPES, 2019).

Essa associação entre esporte e educação é, frequentemente, vista e exibida pelas ONGs como possibilidade de mudança social, contudo a prática esportiva só garantirá resultados contributivos com um processo educacional se for sistematizada e aplicada de forma intencional, que busque o desenvolvimento daqueles que a praticam, e não simplesmente a ocupação do tempo (MACHADO; GALATTI; PAES, 2015). Os projetos precisam incluir em sua estrutura pedagógica tanto a prática quanto a reflexão sobre ela, processo inerente ao desenvolvimento e à formação humana.

A formação aqui compreendida acompanha o que propõe Severino (2012, p. 68-69), no sentido de mediar a existência humana “[...] pelas práticas que se objetivam nas esferas do trabalho, da sociabilidade e da cultura [...] A educação é mediação dessa articulação intencionalizante entre o conhecimento e as práticas históricas". Essa educação só será transformadora se for crítica e disposta a romper os padrões ideológicos hegemônicos.

Souza Neto (2010) concorda que não é direta a relação entre a educação oferecida nas ONGs e a práxis sugerida se, nessa trajetória, faltarem reflexões e discussões sobre a condição humana e sua inserção na história, podendo se manter reducionista e alienadora. Busca-se, portanto, a compreensão que esses ${ }^{1}$ sujeitos têm sobre os processos educativos nos quais estão inseridos. 
A investigação presencial deu-se junto a três ONGs que atuam com projetos esportivos para adolescentes, entre os anos de 2018 e 2020, a fim de ouvir o que essas pessoas têm a dizer sobre o significado desses locais para elas.

Por mais que sejam percebidos pelas organizações como socialmente vulneráveis, por fazerem parte da Política Nacional de Assistência Social (PNAS), os adolescentes são cidadãos, sujeitos de direitos e de conhecimento, pessoas em desenvolvimento, parte integrante e indissociável dos processos educativos nos quais estão inseridos (ARAÚJO, 2014). A ONG apresenta-se como um, senão o único, espaço possível de acesso democrático à prática esportiva.

Dias (2001) destaca que existe uma identificação dos adolescentes com a maneira parcial e antecipada com a qual a sociedade os determina, como se um único aspecto, geralmente nocivo, fosse suficiente para caracterizá-los. Os adultos responsáveis pelo julgamento atribuído a esses sujeitos parecem sentir-se ameaçados pela liberdade de expressão característica da fase e, quase sempre, recorrem ao poder e à autoridade para trazê-los de volta à ordem vigente.

Atribuir à adolescência a condição de período difícil traduz-se em uma resposta superficial, que expressa a incompreensão, a agressividade e a rigidez da sociedade, já que, sentindo-se ameaçada, precisa impor limites aos que buscam transformações (ABERASTURY; KNOBEL, 1981). O adolescente vive em constante alternância de momentos de estabilidade e desestabilidade internas, processo imprescindível para uma identidade em construção.

Somado ao turbilhão psíquico experimentado por essas pessoas, que há pouco eram crianças, tem-se uma sociedade contemporânea que favorece, incessantemente, a perda de referenciais identitários, sobretudo em consequência dos avanços tecnológicos ocorridos desde a virada do século (MALVASI; TEIXEIRA, 2010). Para ambos autores,

as novas configurações da subjetividade são também agenciamentos práticos da vida cotidiana, pois a capacidade de se adaptar, de ser flexível e "aberto às mudanças" tornouse uma necessidade para os mais jovens. Há necessidade de incansável adaptação a novas circunstâncias e possibilidades para conseguir viver no mundo atual. (p. 54-55).

Malvasi e Teixeira (2010, p. 56) observam outra característica existente na sociedade atual, a "intolerância com o sofrimento, próprio ou do outro. Os sentimentos e emoções constitutivos do humano (a tristeza, por exemplo) são patologizados [...] e as soluções são colocadas como da ordem de intervenções técnicas [...]”. Existiria um enfraquecimento ou mesmo uma ruptura nos vínculos sociais, com uma consequente perda ou inexistência de possibilidades de amparo ao sujeito tanto em sua comunidade quanto nos grupos dos quais faz parte, já que todos sofrem mudanças. 
Por esse entendimento, a participação em grupos de atividades esportivas desempenharia um papel estruturante na construção identitária dos adolescentes como sujeitos sociais, uma vez que se caracterizam, principalmente, como espaços de sociabilidade.

Só é possível considerar o adolescente associado às suas instâncias psíquicas internas e aos aspectos presentes no mundo externo a ele, e não de forma isolada, de acordo com Aberastury e Knobel (1981), noção que dialoga diretamente com o pensamento complexo, referencial teórico que embasa o estudo realizado.

\section{Pelas lentes da complexidade}

Para Morin (2000), a compreensão que isola os saberes de seu contexto e da subjetividade dos sujeitos envolvidos torna-se sem sentido. É preciso ter-se em conta que os seres humanos são constituídos por aspectos biológicos, culturais, psíquicos, sociais e espirituais, e que o erro, a incerteza, a desordem e a incompletude fazem parte desse todo. A complexidade é a lente necessária para articular esses elementos, que, ao longo da história, foram isolados para serem compreendidos, característica do pensamento cartesiano (MORIN, 2005).

É necessária uma outra forma de pensar, que religue os saberes antes isolados e que coloque de volta o sujeito em comunhão com o fenômeno a ser investigado (MORIN, 2005). O pensamento linear que separa razão e emoção, sujeito e objeto pode evidenciar alguns elementos, porém, e ao mesmo tempo, pode ignorar outros igualmente pertencentes ao objeto de investigação (MORIN, 2000). A compreensão de problemas multidimensionais e, cada vez mais, complexos exige uma forma de analisálos, também complexa, que conecte sujeito, objeto, observador, as subjetividades envolvidas e os saberes existentes no processo e no contexto.

Compreender o fenômeno esporte sob a luz da complexidade é proposto por Santana (2005), que também se refere a Morin e leva em conta as influências objetivas e subjetivas que a prática esportiva exerce na vida das pessoas, seja para quem planeja, pratica ou assiste ao esporte. Não é possível a continuidade de um pensamento que desconsidera as várias dimensões relativas ao sujeito que faz parte do esporte, tanto como atleta profissional quanto como praticante para uma vida inteira ativa fisicamente.

Morin (2008) organiza três princípios operadores do pensamento complexo, interligados entre si, que favorecem o que ele denomina de reforma necessária do pensamento e que embasam a compreensão das narrativas dos adolescentes participantes da pesquisa realizada. 


\section{Duas lógicas no mesmo lugar}

O reconhecimento das diversas dimensões que compõem os fenômenos - sejam individuais, coletivos, culturais, psicológicos ou biológicos - supõe que aspectos aparentemente contraditórios complementam-se mutuamente em um mesmo evento (MORIN, 2008, 2015). Nomeado dialógico, esse princípio reconhece a complementaridade dos contrários, como a ordem e a desordem na relação ordem-desordem-organização, ambas influenciando umas às outras, necessárias entre si para uma nova organização.

A compreensão do adolescente proposta por Aberastury e Knobel (1981) assemelha-se ao princípio dialógico, pois envolve confusões, contradições, rupturas e ambivalências tanto nas experiências familiares quanto nas sociais. Esses sujeitos em desenvolvimento são ao mesmo tempo crianças e adultos, passando por transformações corporais e emocionais internas e externas, que se constituirão em uma nova identidade apenas quando houver uma aceitação por parte desses adolescentes.

\section{Influências mutuamente recursivas}

Morin (2015) sugere, no segundo princípio, a noção da recursividade existente nos processos, em que o produtor de algo é, ao mesmo tempo, produzido pelo produto que produziu. O processo reprodutivo ilustra essa afirmação, já que origina os indivíduos que são responsáveis pelo processo que os originou, descrevendo, dessa forma, um anel recursivo reprodutivo.

A sociedade e os indivíduos que a compõem caracterizam, igualmente, o processo recursivo de produção mútua e retroativa entre os elementos, já que “[...] é produzida pelas interações entre indivíduos, mas a sociedade, uma vez produzida, retroage sobre os indivíduos e os produz" (MORIN, 2015, p. 74). Esse processo circular de autoprodução e autoconstituição também contribui para a desconstrução do pensamento linear que aponta uma relação direta entre causa e seu efeito.

Malvasi e Teixeira (2010, p. 71) percebem um caminho semelhante quando indicam que a aprendizagem e socialização de adolescentes e jovens acontecem

[...] de acordo com os valores, ritos, crenças, costumes, práticas disponíveis em seu cotidiano e no imaginário social acessível. Aprendem conosco, com os adultos. Às vezes aprendem por meio da nossa indiferença e preconceito.

É necessário ir além da relação causa e efeito, que comumente estigmatiza esses sujeitos e ignora ambivalências da sociedade em que vivem. 


\section{Parte ao mesmo tempo que todo}

Assim como a imagem de um holograma é composta de inúmeros pontos, e cada um deles contém individualmente as informações necessárias do objeto que será representado, o terceiro princípio é denominado de hologramático, ao operar a mesma relação entre unidade e totalidade (MORIN, 2015). Não existe sobreposição de importância na relação parte e todo, mas o reconhecimento da "[...] unidade humana em meio às diversidades individuais e culturais e as diversidades individuais e culturais em meio à unidade humana" (MORIN, 2008, p. 25).

O indivíduo é único e sua condição unitária carrega aprendizagens ancestrais de sua cultura e sociedade, como regras, costumes, hábitos de vida, incluindo a linguagem, processo que o constrói enquanto ser humano e grupo social (MORIN, 2015). É sob esse viés que os adolescentes da pesquisa são compreendidos: únicos enquanto indivíduos com suas singularidades e universais enquanto constituídos da totalidade cultural e social da humanidade.

\section{Objetivamente subjetivo}

A vida imaginária esteve sempre presente objetivamente no desenvolvimento da humanidade, entrelaçada à concretude do mundo externo e manifestada por meio de sonhos, lendas, espíritos, mitos, habitantes da consciência ou de instâncias mais profundas e inconscientes (MORIN, 2012). Decorrente de conceitos psicanalíticos, esse autor propõe que a Projeção, a Identificação e a Transferência (P.I.T.) expressam a subjetividade na objetividade e nomeia essa tríade de complexos imaginários (MORIN, 2003).

A Projeção compreende a “[...] transferência de estados psíquicos subjetivos para o exterior; estes se fixam quer em imagens, representações ou símbolos que parecem, então, existir objetivamente [...]" (MORIN, 2003, p. 89). O processo no sentido oposto, de fora para dentro, é conhecido como Identificação, condição que faz com que o sujeito perceba e sinta como se algo tivesse sido introjetado do meio externo a ele. Ambos os complexos imaginários necessitam da Transferência para passar de uma instância a outra, aspectos projetados ou identificados.

Portanto, a objetividade existe com base na subjetividade, e as narrativas dos adolescentes entrevistados neste estudo sugerem aspectos que corroboram essa noção.

\section{O percurso metodológico da pesquisa}

Severino (2016) indica que a escolha da metodologia investigativa se constrói a partir do desenvolvimento e definição do objeto de estudo; no caso, a busca pelo significado atribuído pelos adolescentes sobre as ONGs das quais participam sugeriu uma abordagem qualitativa de pesquisa. 
Saber o que pensam os adolescentes sobre os projetos dos quais participam aponta para possibilidades de escuta desses sujeitos e favorece a escolha de entrevistas abertas como meio de coleta de dados da pesquisa. Para Szymanski (2018), o momento da entrevista pressupõe uma interação entre entrevistado e entrevistador, e a narrativa desvela significados e intenções de ambos, com sentimentos e emoções que os acompanham o tempo todo.

Morin (2007) se aproxima dessa ideia ao destacar que as emoções presentes na entrevista, paralelamente às informações geradas, são fundamentais à compreensão dos conteúdos coletados. Mesmo aparentemente desafiadora,

\footnotetext{
a questão aberta, a resposta espontânea (sobretudo na análise profunda) traz à fabulação um sentido autêntico, uma riqueza significativa: mas, desta vez, o maior risco de erro se situa ao lado do entrevistador, na sua aptidão em decifrar a mensagem do entrevistado [...] O interesse da entrevista não-dirigida vai além da informação [...] (MORIN, 2007, p. 66-73).
}

Para os adolescentes, a aceitação em participar da pesquisa sugere, ainda, que esses sujeitos têm conhecimentos a serem compartilhados e concordam com os interesses propostos pelo estudo (SZYMANSKI, 2018).

O processo realizado para se chegar aos 23 adolescentes contou, inicialmente, com a receptividade da Rede Esporte pela Mudança Social (REMS), movimento formado por cerca de 38 ONGs no Estado de São Paulo, somando 150 organizações em todo o país. No primeiro contato por correio eletrônico, havia a descrição do objeto da pesquisa e a metodologia de coleta de dados. Ao todo, três ONGs interessaram-se em receber a pesquisa, a saber: Associação Hurra (São Paulo), Fundação Esportiva Educacional Pró Criança e Adolescente (EPROCAD, em Santana de Parnaíba) e Instituto Passe de Mágica (São Paulo/Diadema). Todas elas indicam, em seus sítios eletrônicos, que atuam com práticas esportivas para a educação e o desenvolvimento dos adolescentes.

Houve uma primeira visita às ONGs para apresentação do estudo e convite para as entrevistas, feito diretamente aos adolescentes participantes dos projetos. O único critério seletivo estipulado foi a idade, entre 13 e 18 anos. Ao todo, 60 adolescentes manifestaram interesse em participar, contudo, entre as etapas seguintes de assinatura dos documentos previstos pelos procedimentos éticos da pesquisa (Termos de Consentimento e Assentimento Livres e Esclarecidos) e realização da entrevista, cerca de dois meses após o primeiro contato, esse número inicial caiu para 23.

Prosseguiu-se com o agendamento das entrevistas, de acordo com as atividades que os adolescentes desenvolviam nos projetos. Foi solicitado às coordenações que providenciassem um 
espaço exclusivo para os encontros com os entrevistados, de modo a garantir um ambiente seguro e sigiloso, solicitação que foi atendida nas três organizações.

Todas as entrevistas iniciaram-se com uma rápida apresentação pessoal da pesquisadora, dos objetivos da pesquisa e da maneira como aconteceria a entrevista, a fim de verificar possíveis dúvidas. A solicitação para a gravação do áudio, necessária para o processo de transcrição posterior, foi aceita por todos.

Szymanski (2018) sugere que a entrevista seja feita a partir de uma questão que ela denomina de desencadeadora, um estímulo aos processos reflexivos do entrevistado, com liberdade de tempo suficiente para uma livre expressão de ideias e emoções, e assim foi feito.

O que significa para você participar da ONG (nome da ONG)? desencadeou as narrativas, e, quando ocorreu algum aspecto não compreendido, um pedido de explique melhor o que você quis dizerer com isso foi feito. O tempo das entrevistas variou entre dois minutos e meio e 23 minutos e 42 segundos de livre expressão dos entrevistados.

\section{Com a palavra, os adolescentes!}

Uma primeira organização conceitual de análise, nomeada de adolescência dialógica, destaca trechos das entrevistas que se complementam, mesmo sendo aparentemente contrários entre si. A afirmação [...] en gostava de participar só que eu não dava a mínima pro curso, né, pra ONG em si [...] eu queria fazer uma coisa, só que eu não tava ligando [...] nega o pensamento linear que pressupõe uma concordância com o gostar, no caso, se gosta, há interesse.

Outra adolescente relata que [...] muitas vez̧es a pessoa pensa que não vai conseguir. Mas, é aí que junta o sentido, o sentido de tudo [...] nunca desistir dos meus sonbos, não pretendo desistir tão cedo [...] sabe, porque agora nada pra gente é fácil [...], expressão que é respaldada por Morin (2015) ao destacar que os contrários interagem entre si e produzem uma organização complexa.

O professor aparece em um relato como decisivo para um adolescente, em relação à sua continuidade na prática esportiva mesmo diante de alguns elementos desfavoráveis, o que indica a aceitação da diversidade de perfis e condições individuais:

[...] eu sei que eu sou gordo, todo mundo me xinga [...] você é ruim, você num presta para jogar basquete... o professor [...] falou [...] se anima, vai pra cima e faz o seu melhor. Falei tá bom. Ai, agora eu tô jogando basquete [...] o basquete, pra todo mundo, é um motivo de conforto, magro, gordo, de outras cores, tudo, lá não tem racista [...].

O princípio dialógico "[...] comporta a ideia de que os antagonismos podem ser estimuladores e reguladores" (MORIN, 2005, p. 190), afirmação que se verifica nesse relato. De 
modo semelhante, a razão e a demência coexistem, interagindo entre si, condição possível no ambiente da ONG, segundo uma outra adolescente:

[...] eu era uma pessoa muito briguenta, eu aprendi a não ser assim, porque tudo pra mim se resolvia na briga [...] e a ONG, ela me ensinou que não era daquele jeito [...] eu não preciso bater pra mim resolver as situações da vida [...] os professores sempre tiveram muita paciência comigo [...].

A referência que a adolescente faz à $O N G$ e aos professores sugere que as práticas propostas pela organização e pelos professores influenciam a formação humana que acontece nesses locais. A percepção dessa influência por parte dos adolescentes relaciona-se com o segundo princípio operador proposto por Morin (2015), denominado recursivo, que ilustra mais um tema de análise e tem a relação com os professores como aspecto a ser destacado.

A interdependência existente entre quem produz e o que é produzido aparece em uma narrativa, quando o adolescente qualifica sua relação com o professor [...] é boa porque eu ajudo ele, ele me ajuda e... os dois se entende, por isso que é boa [...]. Morin (2012) sugere um ciclo mutuamente autoprodutivo de influência, em que o adolescente percebe tanto o que o professor produz nele quanto o que ele produz de volta no professor.

Um sistema recursivo que envolve a explicação e a compreensão da explicação é percebido no discurso de outro adolescente, que se aproxima da recursão ética proposta por Morin (2017): [...] aqui é muito legal [...] o que você faz de errado aqui você pensa lá, lá na frente [...] a ONG ela ajuda você muito mais no futuro [...] tipo uma segunda escola, só que, ela nos explica o que nós tamo fazendo de errado [...].

Outra adolescente reconhece a influência do professor no seu desenvolvimento, ao afirmar que [...] a gente nunca vai ter medo de aprender o novo, a gente sempre vai ter mais vontade de aprender o novo, quando a gente tem um educador mais próximo de nós [...]. Influência percebida também no discurso de outra adolescente, que demonstra a intenção de produzir algo resultante do processo que a influenciou:

[...] esse é aquele lugar que marca a gente pra sempre, como uma coisa boa, que me inspirou a querer, futuramente, a criar minha própria ONG pra ajudar as mulheres e adolescentes [...] que não entram muito no ramo de trabalho [...] futuramente eu pretendo conseguir ajudar elas [...].

Para Morin (2005, p. 111-112), “[...] um pensamento do pensamento capaz de retroagir sobre o pensamento, assim como a consciência de si permite retroagir sobre si." descreve o anel recursivo percebido nos trechos citados.

O terceiro tema de análise acompanha o operador hologramático, que "põe em evidência este aparente paradoxo das organizações complexas, em que não apenas a parte está no todo, como o todo está inscrito na parte.” (MORIN, 2008, p. 94). 
Um adolescente reconhece sua condição unitária dentro de uma totalidade diferente e presente, ao mesmo tempo, na sua constituição enquanto sujeito, além de expressar a ideia de respeito e solidariedade em relação aos outros:

[...] participar daqui do projeto é uma grande experiência, e é única, né... não é todo mundo que tá tendo essa oportunidade [...] tem gente que é mais velho [...] mais nova [...] tem que se acostumar e dar oportunidade para todos [...].

Para Morin (2015, p. 75), “[...] o adquirido no conhecimento das partes volta-se sobre o todo [...] pode-se enriquecer o conhecimento das partes pelo todo e do todo pelas partes, num mesmo movimento produtor de conhecimentos.", que conecta os princípios recursivo e hologramático.

Os três operadores não existem de maneira isolada, mas em contínua interação e movimento (MORIN, 2015), exemplificados no discurso de um dos entrevistados:

[...] o projeto significa como um meio de en relaxar, esquecer mens estudos, sentir que eu sou... que eu tenho uma parte livre da minha vida, que eu tenho um espaço só pra mim [...] cada momento que eu tenho uma aula aqui, sinto como se en tivesse meu lugar no mundo [...].

Há o reconhecimento de que a ONG é uma parte do todo (o mundo), da mesma forma que o adolescente se percebe como parte (indivíduo livre) no todo; a aula, que é todo, tem espaço para ele, único e todo ao mesmo tempo.

O mundo objetivo entrelaçado na subjetividade descreve o quarto conjunto de ideias organizadas para analisar os dados dos adolescentes, de acordo com o que Morin (2003) indica como a vida imaginária das pessoas infiltrada na vida prática. A relação que uma adolescente estabelece entre o que se passa na sua mente e a realidade é direta, como se seus pensamentos e desejos fossem capazes de conduzir os acontecimentos:

[...] sabe quando você acorda e cê fala: hoje o meu dia vai ser maravilhoso, en vou fazer de tudo pra dar certo? E foi muito maravilhoso, eu recebi tantos elogio, fiz vários gol no festival, nossa, foi muito maravilhoso [...].

Para Morin (2003, p. 98), a projeção caracterizada pela fala acima descreve a razão paradoxalmente subjetiva que parece “[...] reduzir a explicação à identificação (explicar é identificar fenômenos, aparentemente heterogêneos, uns aos outros)". Identificação e projeção aparecem nos relatos de quase todos os adolescentes, ao sugerirem que a ONG é como a casa ou a família, sobretudo quando se referem ao acolhimento recebido, em especial pelos professores.

Os trechos seguintes corroboram essas ideias, e as frases são de dez adolescentes diferentes, identificados por letras sequenciais: 
[...] esse lugar aqui é maravilhoso [...] a minha segunda casa [...] eles sempre se preocuparam com a gente [...] então, eles sempre foram a minha família [...] (A);

[...] é tipo uma terceira casa pra mim [...] nossa casa é a primeira, a escola é a segunda e a ONG é a terceira [...] nossa terceira casa explica mais do que a segunda, ela nos ajuda mais [...] (B);

[...] pra mim é uma segunda casa [...] é onde eu mais fico [...] eu saio de casa, aí venho pra cá e volto pra casa e vou pra escola, é sempre essa rotina [...] foi o lugar que mais me acolheu e aonde en gosto de ficar [...] (C);

[...] é, tipo, a minha segunda casa, porque eu tô aqui desde pequeno, e eu fui sempre bem acolbido aqui, né [...] as pessoas te dão, falam ó faz isso, dá conselho, te ajuda [...] (D);

[...] a ONG significa uma casa pra mim [...] ela já me fez. eu me comunicar bastante [...] eu era muito nervosa [...] não conseguia nem falar com as pessoas [...] ela me incentivava a falar com todo mundo [...] isso me ajudou bastante [...] (E);

[...] eu considero mais aqui minha casa do que minha própria casa [...] eu não tenho amigos aqui, eu tenho irmãos

[...] considero até os professores como pais e mães [...] a ONG, ela sempre me ensinou muito com amor [...] (F);

[...] pra mim é como se fosse uma família [...] me sinto como se eu estivesse em casa [...] o professor me inspira [...] dá aqueles conselhos [...] eu me sinto como se eles fossem meus pais, uma mãe, irmãos, sempre ajudando, me apoiando [...] (G);

[...] lá em casa as coisas não são muito fáceis e tal, aí aqui era muito meu refúgio, antigamente [...] aqui é como uma familia $[\ldots]$ (H);

[...] o professor é como um segundo pai pra mim, a professora é como uma segunda mãe [...] quando eu sair, eu vou sofrer muito [...] (I);

[...] eu aprendi muitas coisas aqui [...] conversar com pessoas, é, ser gentil [...] essas coisas assim, bem de mãe mesmo, sabe, mãe e pai ensinando, é isso [...] (J).

Os adolescentes sugerem que as ONGs são espaços que dispõem de atenção a cada um que os acolhem pelas estratégias utilizadas nas atividades, principalmente pelo diálogo - e percebem a influência desse contexto na sua educação e formação humana.

\section{Considerações finais}

Por mais que se reconheça o alicerce político que acentuou a existência das ONGs, como resultado de décadas de não investimento em políticas que garantam direitos sociais, esses espaços de aceitação, diálogo e propostas pedagógicas organizadas atendem a uma parcela da população que, em sua maioria, não seria atendida de outra forma.

As narrativas adolescentes sugerem que é necessário compreendê-los com base em aspectos internos e externos, que fazem parte tanto da adolescência quanto do contexto no qual estão inseridos, em sua condição de unidade e todo ao mesmo tempo. As ONGs aceitam os diferentes adolescentes como parte que compõe o todo e como o próprio todo, já que cada um traz uma totalidade histórica, cultural e subjetiva. Os professores são indicados como maiores responsáveis por esse acolhimento e pelo incentivo ao diálogo como aspecto significativo para os adolescentes.

A convivência dos adolescentes entre si e com os professores das ONGs favorece a recursividade caracterizada pela influência mútua e retroativa, em que todos são produtos e produtores das relações e reconhecem o quanto são influenciados e influenciam os outros. Existe uma consciência por parte desses sujeitos de que as relações humanas são interdependentes e de que cada pessoa produz e é produzida por aquilo que produziu. As práticas desses espaços 
influenciam a educação e a formação humana dos adolescentes, com ênfase em valores como a solidariedade, o respeito e a diversidade.

A subjetividade está presente nos relatos e nas ONGs por meio das emoções, dos desejos, das crenças e das razões de cada um, expressando a vida imaginária dos adolescentes entrelaçada na vida prática. A ONG não é a casa deles, mas, por motivos diversos relacionados ao acolhimento e à afetuosidade com que são tratados, passa a ser percebida como um lar, seja por projeção ou identificação, de acordo com os complexos imaginários.

Conclui-se que as ONGs apresentam aspectos significativos para os adolescentes quanto à sua educação e formação humana, e que o estudo aponta caminhos possíveis para se atuar com esses sujeitos.

${ }^{1}$ A designação masculina ao longo do texto, ao indicar sujeitos e adolescentes, tem o único propósito de dar fluidez à leitura, uma vez que, mesmo reconhecendo a importância de se utilizar uma escrita representativa para os outros gêneros, ainda não existe um consenso acadêmico sobre qual termo melhor abrangeria esse contexto.

\section{Referências}

ABERASTURY, Arminda; KNOBEL, Maurício. Adolescência normal. Porto Alegre: Artes Médicas, 1981.

ARAÚJO, Joselaine de. A educação não formal e as políticas públicas para a juventude em situação de risco e vulnerabilidade social. 2014. 84f. Dissertação (Mestrado em Educação) - Universidade do Oeste Paulista - Unoeste, Presidente Prudente, 2014.

BERCLAZ, Márcio Soares; LOPES, Ana Christina Brito. A invisibilidade do Esporte e da Cultura como Direitos da Criança e do Adolescente. In: Revista Direito e Práxis UERJ, Rio de Janeiro, v. 10, n. 2, p. 1430-1460. 2019. Disponível em: https://www.epublicacoes.uerj.br/index.php/revistaceaju/article/view/40696. Acesso em: 7 set. 2020.

DIAS, Elaine Teresinha Dal Mas. Adolescência: entre o passado e o futuro, a experiência. 2001. 200f. Tese (Doutorado em Psicologia) - Instituto de Psicologia da Universidade de São Paulo, Departamento de Psicologia da Aprendizagem, do Desenvolvimento e da Personalidade, Universidade de São Paulo - USP, São Paulo, 2001.

GOHN, Maria da Glória. O protagonismo da sociedade civil: movimentos sociais, ONGs e redes solidárias. São Paulo: Cortez, 2005.

MACHADO, Gisele Viola; GALATTI, Larissa Rafaela; PAES, Roberto Rodrigues. Pedagogia do Esporte e Projetos Sociais: Interlocuções sobre a Prática Pedagógica. Movimento, Porto Alegre, v. 21, n. 2, p. 405-418, abr./jun. 2015. Disponível em:

file://C:/Users/Samsung/Downloads/48275-231857-1-PB.pdf. Acesso em: 1 jul. 2019.

MALVASI, Paulo Artur; TEIXEIRA, Maria de Lourdes Trassi. Violentamente pacificos: desconstruindo a associação juventude e violência. São Paulo: Cortez, 2010. 
Marco Regulatório das Organizações da Sociedade Civil (MROSC). 2014. Disponível em: https://mapaosc.ipea.gov.br/ajuda.html. Acesso em: 8 set. 2020.

MORIN, Edgar. A cabeça bem-feita: repensar a reforma, reformar o pensamento. 15. ed. Rio de Janeiro: Bertrand Brasil, 2008.

MORIN, Edgar. As duas globalizaçôes: Complexidade e comunicação, uma pedagogia do presente. $3^{\mathrm{a}}$ ed. Porto Alegre: EDIPUCRS. 2007. Disponível em:

http://www.pucrs.br/edipucrs/digitalizacao/diversos/978-85-7430-625-4.pdf. Acesso em: 4 dez. 2017.

MORIN, Edgar. Ciência com consciência. 8. ed. Rio de Janeiro: Bertrand Brasil. 2005a. Disponível em: https://www.academia.edu/6449183/Ciencia_com_Consciencia_-_Edgar_Morin. Acesso em: 11 abr. 2018.

MORIN, Edgar. Complexos imaginários. In: PENA-VEGA, Alfredo; ALMEIDA, Cleide Rita Silvério de; PETRAGLIA, Isabel. Edgar Morin: ética, cultura e educação. São Paulo: Cortez, 2003. p. 89-103.

MORIN, Edgar. Introducão ao pensamento complexo. 5. ed. Porto Alegre: Sulina, 2015.

MORIN, Edgar. O Método 5: a humanidade da humanidade. 5. ed. Porto Alegre: Sulina, 2012.

MORIN, Edgar. O Método 6: ética. Tradução: Juremir Machado da Silva. 5. ed. Porto Alegre: Sulina, 2017a.

MORIN, Edgar. Os sete saberes necessários à educação do futuro. 2. ed. São Paulo: Cortez; Brasília: UNESCO, 2000. Disponível em:

http://arquivos.info.ufrn.br/arquivos/2012133176826a1035842e1211 faee999/setesaberesmorin. pdf.pdf. Acesso em: 24 nov. 2017.

SANTANA, Wilton Carlos de. Pedagogia do esporte na infância e complexidade. In: PAES, Roberto Rodrigues; BALBINO, Hermes Ferreira. Pedagogia do esporte: contextos e perspectivas. Rio de Janeiro: Guanabara Koogan, 2005.

SEVERINO, Antonio Joaquim. Educaşão, sujeito e história. 3. ed. São Paulo: Olho d’ Água, 2012.

SEVERINO, Antonio Joaquim. Metodologia do trabalho científico. 24. ed. São Paulo: Cortez, 2016.

SOUZA NETO, João Clemente de. Pedagogia social: a formação do educador social e seu campo de atuação. In: Cadernos de Pesquisa em Educação PPGE-UFES, Vitória, v. 16, n. 32, p. 29-64, jul./dez. 2010. Disponível em:

http://www.periodicos.ufes.br/educacao/article/view/4404/3446. Acesso em: 4 out. 2018.

SZYMANSKI, Heloísa (org.). A entrevista na pesquisa em educação: a prática reflexiva. 5. ed. Campinas: Autores Associados, 2018.

TELLES, Vera da Silva. Direitos sociais: afinal do que se trata? Belo Horizonte: UFMG, 1999. 